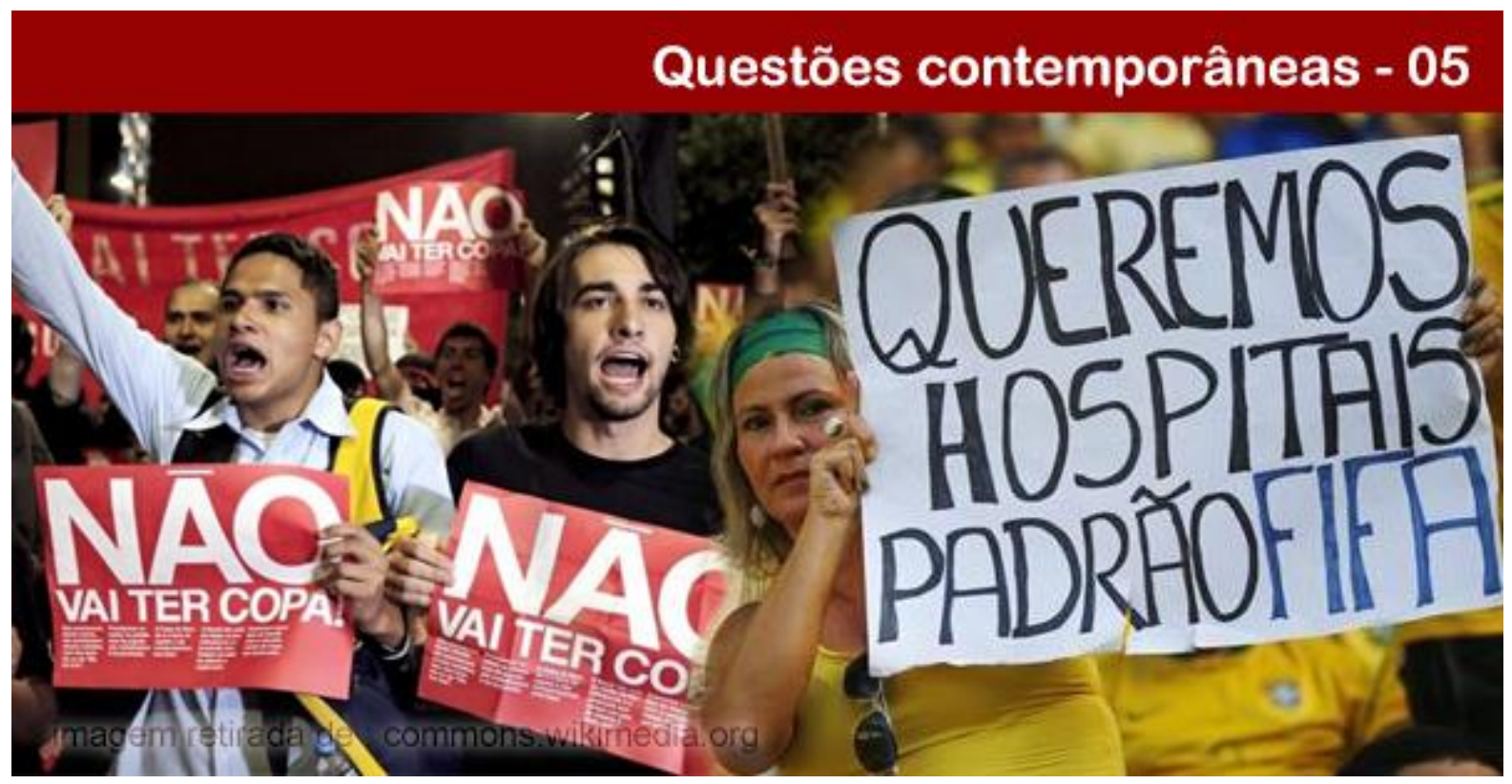

\title{
CARNAVANDALIRIZAÇÃO: UMA REDE DE ARTEATIVISMO
}

\section{Paula Gorini Oliveira}

Mestre em Novas Tecnologias de Comunicação e Cultura - Universidade do Estado do Rio de Janeiro (UERJ). E-mail: paulagorini@gmail.com.

Resumo: A rede de arteativismo que propõe-se pensar nesse artigo conecta iniciativas estéticas de protesto, formas coletivas de mobilização e colaboração e a influência das novas tecnologias de comunicação na produção de subjetividade em nossa contemporaneidade. A pesquisa se vale de um contexto específico, os protestos anticopa de 2014, a partir do acompanhamento de um coletivo: Atelier de Dissidências Criativas e se expande na produção de um discurso que atravessa o tempo específico da copa, e permanece como processo investigativo e criativo. A pesquisa parte da premissa de que há uma modificação na produção, divulgação e consumo de informação, mas também observa a produção de sentido em uma experiência de comunicação que se caracteriza pelo esmaecimento dos limites entre arte e política.

Palavras-chave: Comunicação. Estudo de redes. Arte. Ativismo. Colaboração.

\section{CARNAVANDALIRIZAÇÃO: A STUDY OF ART ACTIVISM NETWORK}

Abstract: The art activism network we propose to discuss in the following paper connects artistic initiatives of protest, collective mobilization, and the impact of new technologies of communication in the production of subjectivity. The research relies on a specific context, the Anti-World Cup protests, in 2014, from the monitoring of an artistic collective, "Atelier de Dissidências Criativas", and is expanded as a continued debate that crosses the specific time of the World Cup protests, remaining as a creative work in process and investigative space for art activism production. The research starts from the premise that there is a change in the production, distribution and consumption of information, but also observes the production of subjectivity in a communication experience that fades the boundaries between art and politics.

Keywords: Communication. Network studies. Art. Activism. Collaboration.

\section{Introdução}

O presente artigo é o resultado de uma pesquisa etnográfica na área de comunicação e cultura, com enfoque no estudo de redes, e observa as relações que se estabelecem em ações 
de arteativismo. A rede de arteativismo que propomos pensar nesse artigo conecta iniciativas estéticas de protesto, formas coletivas de mobilização e colaboração e a influência das novas tecnologias de comunicação na produção de subjetividade na contemporaneidade.

A pesquisa teve seu ponto de partida nos protestos anticopa, realizados no período da Copa do Mundo 2014, no Brasil, e acompanhou um coletivo que trabalha no limiar entre arte e ativismo, chamado "Atelier de Dissidências Criativas". Conhecido simplesmente como "Dissidências", o coletivo tem por característica criar novas narrativas de protesto e manifestação, centrados no lúdico provocativo, num cruzamento entre política e arte.

Uma de suas mais expressivas narrativas de protesto tomou força e representatividade pelo nome de "Carnavandalirização", que propõe a junção da estética carnavalesca e a poética lírica do discurso artístico ao engajamento político de enfrentamento. O nome "Carnavandalirização" surge da necessidade de reinventar a presença das manifestações como território privilegiado de certas correntes políticas, ampliando seu campo de discussão, e como uma sátira ao peso semântico da palavra "vandalismo", como é representada na mídia. Este é o ponto de partida, uma experiência tangível, da qual a pesquisadora pôde participar como "observadora privilegiada" .

O grupo, que se reúne na cidade do Rio de Janeiro, teve uma expressiva participação nos protestos anticopa 2014, e, do ponto de vista do estudo de rede, se constrói através da mobilização pelas redes sociais, pelos encontros presenciais, pela prática de produção de materiais criativos de protesto. Suas ações incluíram: a produção de figurinos, como os de personagens da "Quadrilha da FIFA: o casamento do Phoder Público com as Empreiteiras"; a oficina de serigrafia com frases de protesto como "Copa, Cozinha e Grana Lavada", "Copa pra quem?”, ou “Com teto/sem FIFA”...; além da participação ativa na produção de informação alternativa à grande mídia, com um grupo de trabalho dedicado a pensar e produzir conteúdo anticopa, reflexivo ou de denúncia; e a colaboração na plataforma Agrega.la ${ }^{2}$.

\section{Uma rede para acompanhar}

\footnotetext{
${ }^{1}$ Durante o período das ações de protesto anticopa, a pesquisadora frequentou a Casa Nuvem, sede do coletivo, localizada na Lapa. Participou da organização de algumas ações realizadas, de grupos de email e facebook, e esteve presente em reuniões abertas do coletivo.

${ }^{2}$ Portal na internet que reúne numa mesma interface as publicações dos principais grupos de mídia livre: CMI, Projetação, Vinhetando, Mídia Ninja, A Nova Democracia, etc.
} 
Trabalhar com a "Rede" de arteativismo implica pensar que nenhuma ação se dá de forma isolada. O contexto em que se inserem as narrativas de carnavandalirização diz respeito a uma rede de atuações, que conecta materiais lúdicos diversos e a habilidade para tratá-los (não à toa a presença de artistas plásticos no coletivo); conecta ações específicas na produção de registros em texto, vídeo e imagem; que adota uma postura "livre" (por isso a associação com midialivristas), para garantir que as ações não se percam em rótulos préformulados pelas práticas da vinculação dos Meios de Comunicação de Massa; conecta experiência prévia de seus participantes de forma transdisciplinar, que vão desde a produção cultural ao ativismo político, documentação e elaboração de materiais; e, por fim, conecta-se com outros carnavais de protesto, outras narrativas de protesto lírico que exploram o cruzamento entre arte e política, no Brasil e em outros países.

Como proposta metodológica, optou-se por fazer um exercício de "descrição etnográfica", com base na abordagem proposta pelo autor Bruno Latour, a TAR - Teoria Ator-Rede (LATOUR, 2008). O que consiste dizer que, nas narrativas acerca do caso estudado, tentaremos deixar o objeto falar, observar quais são os dados que deixam vestígio nas relações entre os vários procedimentos que tramam as ações de arteativismo e "escutar" os atores que nela se revelam. Buscaremos planificar as forças de ação entre sujeito e objeto, entendendo que não há hierarquia entre estes e que, portanto, o objeto é também agente (atorrede) na construção de uma abordagem em rede (por isso a escolha em incluir o sujeito também na escrita do texto).

Não há uma verdade ou enunciado pré-estipulado que a pesquisa pretenda seguir, ou uma pergunta que a pesquisa pretenda responder, mas fluxos de movimento que dão a ver um certo fenômeno a se acompanhar. Diferente das metodologias tradicionais, que implicam em um distanciamento do objeto, em experimento que comprove hipóteses em vez de experiências, o que é proposto com base na TAR e no método cartográfico é a abordagem do "saber com", que implica em se colocar ao lado do objeto, planificando seu posicionamento de maneira não hierárquica, possibilitando que o objeto protagonize.

Patrícia Azambuja, em sua tese de doutorado, "Cognição e mediação técnica..." (2012), que utiliza a TAR como abordagem metodológica, defende como os vestígios que são visíveis na rede, são também definidores da própria rede, uma vez que os atores não são dados de antemão. 
O ator (ou actante) se estrutura pelo efeito provocado por suas ações, o que não se trata de um indivíduo único, pois parte de um conceito heterogêneo, visto como híbrido. A rede se forma, então, pelas diferentes conexões que surgem nessas relações imbricadas, por isso são complexas e imprevisíveis. Essa estrutura construída não é apenas humana, é uma relação também material, que parte de um processo mais amplo, tem uma história e interfere nas relações entre homens (AZAMBUJA, 2012, p. 27).

Não é possível pré-estabelecer quais atores poderão ser observados na rede, antes de entrar em "contato" com ela. Por isso também, o trabalho de campo, o acompanhamento, o observar "com", são alguns dos procedimentos necessários para fazer ver a rede. Para Letícia de Luna Freire, em seu estudo "Seguindo Bruno Latour" (2006), a noção de rede, na TAR, "remete a fluxos, circulações e alianças, nas quais os atores envolvidos interferem e sofrem interferências constantes" (FREIRE, 2006, p. 55).

A cartografia, por sua vez, tal qual pensada por Passos et al (2009), é uma formulação metodológica adequada à investigação de processos de produção de subjetividade, produção de conhecimento num tempo processual. A sistematização do método não implica regras ou protocolos rígidos, pois entende que ao acompanhar processos "não podemos ter predeterminada de antemão a totalidade dos procedimentos metodológicos" (PASSOS; KASTRUP; ESCÓSSIA, 2009, p. 13). Os autores propõem “pistas" que guiam o cartógrafo, que servirão como referências para o desenvolvimento da pesquisa que se constrói em seu próprio caminhar.

$\mathrm{O}$ 'saber com' aprende com os eventos à medida que os acompanha e reconhece neles suas singularidades. [...] Ao invés de controlá-los, os aprendizes-cartógrafos agenciam-se a eles, incluindo-se em sua paisagem, acompanhando os seus ritmos (PASSOS; KASTRUP; ESCÓSSIA, 2009, p. 149).

Assim como Latour (2008) propõe não interpretar os vestígios, os autores de "Pistas para o método da cartografia..." afirmam que a construção de um pensamento deve seguir rotas não interpretativas e não lineares. A cartografia, assim, é um mapa móvel que não possui sentidos e entradas únicas, são múltiplas as possibilidades de acesso a esse mapa. O sentido da cartografia é de "acompanhamento de percursos, implicação em processos de produção, conexão de redes e rizomas” (PASSOS; KASTRUP; ESCÓSSIA, 2009, p. 10).

Através de experiência própria e atitude de observação participante, pretendemos produzir narrativas sensíveis sobre possíveis mudanças na maneira de se estar em um protesto, seus possíveis desdobramentos lúdicos e estéticos, sua atuação como discurso- 
imagem. E, dessa forma, observar a relevância de se refletir sobre um espaço que se abre diante do fenômeno da carnavandalirização, que parece estar diretamente relacionado à produção de sentidos na atualidade, a partir de uma experiência estética-política-vivencial. Por fim, pretendemos traçar as possíveis relações do estudo de caso da carnavandalirização na rede de arteativismo.

Nesse aspecto, serão utilizados: diários de campo, fotos, textos e vídeos de divulgação; registros e impressões de reuniões do grupo, documentação/registro de atos e entrevistas, quando necessário.

\section{Breve Histórico: com.posições.políticas}

O embrião do projeto Atelier de Dissidências Criativas (2014) pode ser identificado a partir do encontro Iberoamericano "Composições Políticas" (2011), desenvolvido como um braço do Festival Panorama ${ }^{3}$, mas com direção e curadoria autônomas. O "Composições", durante uma semana, apresentou mesas redondas, performances, residências artísticas, workshops e espetáculos, além de uma exposição de fotos e um cineclube. A linha curatorial do programa, que promoveu o encontro de artistas, pesquisadores, estudantes e produtores, em torno do eixo "corpo político", se destacou pela aproximação da arte com ativismo político. Alguns nomes de reconhecimento internacional participaram do encontro, como a dupla inglesa "The Yes Men", que além de fazer uma palestra "Ativismo de gravata", facilitou um workshop durante o encontro.

O "Composições Políticas" foi idealizado e dirigido por Isabel Ferreira e Eduardo Bonito (esse último era também diretor e curador do Festival Panorama). Foi o primeiro encontro, que funcionou também como minifestival, a trazer à cena cultural do Rio uma diversidade tão grande de fazedores, pensadores e produtores de arteativismo com enfoque na política do corpo. $\mathrm{O}$ encontro contou ainda com uma residência artística com uma dupla de argentinos "Erroristas"; um workshop de pós-pornô com a espanhola Maria Llopes; um espetáculo com os africanos Boyzie Cekwana e Parnaíba Gabriel, "Ikomati Manifesto"; a estréia do espetáculo queer "Travesqueens", dos artistas brasileiros Ricardo Marinelli, Erivelto Viana e Elielson Pacheco; uma performance com a "extremista" do corpo com a

\footnotetext{
${ }^{3}$ Festival de dança contemporânea, criado em 1991 pela coreógrafa Lia Rodrigues, e que já faz parte do calendário cultural da cidade do Rio de Janeiro.
} 
mexicana Rocio Bolívar (Congelada de Uva); e mesas redondas com pensadores e artistas que atuam no campo do "corpo dissidente".

Em sua primeira apresentação, o "Composições" estava inserido no programa do Festival Panorama, na estrutura física, logística e administrativa do festival. Porém, essa associação com o festival serviu como um trampolim conceitual para formatar um encontro de arteativismo e colocar em ação uma pesquisa que já havia sido iniciada por seus idealizadores. Passado o formato de minifestival e de encontro, o "Composições" seguiu uma trilha frágil, incerta, tateou outros formatos ${ }^{4}$, mas ainda estava vinculada à estrutura do Panorama. Algo que, num segundo momento, se tornou fator complicador, pois o Festival Panorama (Associação Cultural Panorama) guarda relações ético-contratuais com seus principais apoiadores, que limitavam a atuação ativista do "Composições".

Era preciso ser autônomo e independente e garantir assim sua liberdade de discurso, uma vez que este parece ser um pressuposto para qualquer ação ativista, e qualquer incoerência neste aspecto enfraqueceria seu enunciado.

\section{Uma casa chamada Nuvem}

É quando entra em cena um novo espaço na cidade do Rio de Janeiro, a Casa Nuvem, localizada na Lapa, a poucos passos do Beco do Rato. Um sobrado que servia de residência a uma senhora que faleceu, com uma garagem no andar térreo, parecia o espaço ideal para abrigar alguns projetos culturais cariocas que estavam sem sede. Entre eles, motivo pelo seu nome, a Nuvem Móvel ${ }^{5}$.

Junto com a Nuvem Móvel, que precisava de um local para montar sua oficina de eletroacústica, armazenar equipamento e centralizar sua administração, somou-se outro grupo de cicloativismo, o Ciclo Currier, que atua diariamente em horário comercial fazendo entregas pela cidade de bicicleta, além de manter permanentemente ( 24 horas) uma oficina mecânica de bicicleta. Juntaram-se também a empresa de sonorização Foguete e a dupla de produtores Isabel Ferreira e Eduardo Bonito, que iniciaram os encontros do Atelier de Dissidências Criativas na casa.

\footnotetext{
${ }^{4}$ Em 2012, também durante o Festival Panorama, realizou-se um ciclo de debates e mostra de vídeos, inspirados no "Composições", em parceria com a agência inglesa de live art, LADA: "Corpo-Cópia: Library of Performing Rights".

${ }^{5}$ Grupo de cicloativismo, que produz festas itinerantes organizadas em grupos de ciclistas, incluindo a estrutura de áudio, DJs, luzes, etc.
} 
Após um ano de adaptação ao novo espaço, obras de melhoramento e espaço de coworking $^{6}$, a Casa Nuvem abriu chamada pública para se tornar um espaço de construção coletiva e autogestão, em fevereiro de 2014. Atualmente conta com uma média de 20 associados, que se reúnem pelo menos uma vez ao mês para definir os rumos, ações, melhorias e dinâmicas da casa. Como parte integrante do grupo de associados, 10 pessoas são também integrantes do grupo Dissidências ${ }^{7}$.

Desde fevereiro de 2014 (junto com a entrada de novos associados na Casa Nuvem), funciona regularmente, todas as quintas-feiras, o Atelier de Dissidências Criativas. Em seus primeiros meses reuniu artistas, pesquisadores e produtores, em palestras, mesas redondas, mostra de filmes, etc. Ao se aproximar do evento da Copa, as atividades se focaram mais na elaboração de material artístico ativista (como os já citados figurinos, atelier de silk, adereços de carnavandalirização, entre outros), e na produção de textos, vídeos e fotos de conteúdo anticopa pelo grupo de trabalho de mídia.

\section{Uma Imagem de Protesto}

Optamos por investigar a rede de arteativismo pelo fenômeno da carnavandalirização, pela hipótese de uma "forma-protesto" que emerge a partir de uma prática de manifestação diferenciada, pela mobilização e documentação que atravessam os usos tecnológicos de comunicação (e como isso produz sentido como imagem de protesto), e pelo conceito de arteativismo como subversão pela estética e pelo prazer.

Figura - 1: Divulgação Facebook: ato na praia de Copacabana, junto com o Dia do Orgulho LGBT. 28/06/14.

\footnotetext{
${ }^{6}$ Coworking é um conceito que está em voga, em que profissionais autônomos unem recursos em uma mesma estrutura física. Dividindo os custos de aluguel e manutenção de um espaço comum, o coworking possibilita também a troca pela convivência.

7 As informações dispostas no texto foram recolhidas das assembléias do grupo de associados, do qual a pesquisadora também participa.
} 


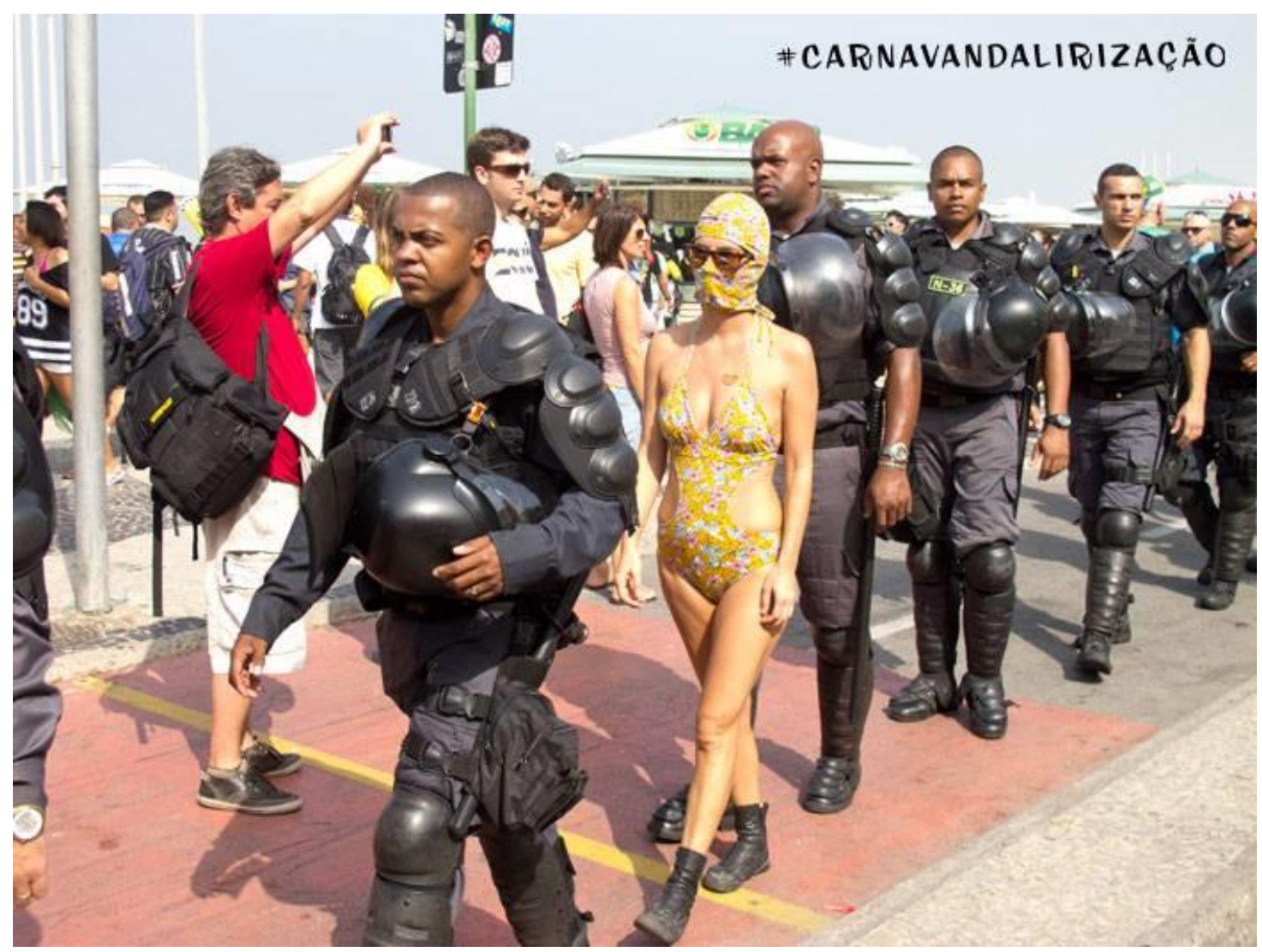

Fonte: https://www.facebook.com/pages/Carnavandalirizacao.

As ações do "Carnavandalirização" foram organizadas pelo grupo do "Dissidências", como um desdobramento de seus encontros. Para divulgação e mobilização de público, foi criada uma comunidade na rede social Facebook (criação em 09/06/2014), com o mesmo nome. Na página da comunidade é possível ter acesso ao histórico de ações, desde sua criação, e algumas informações básicas sobre o grupo. Assim está descrito o "sobre":

O Carnaval faz dos nossos corpos território político. (...) No Carnavandalirismo, a ironia e o humor substituem a testosterona desestruturando a hipermasculinidade das táticas de confronto tradicionais. O corpo, a música e a dança se convertem, desta maneira, em ferramentas poderosas de desarticulação da violência policial e midiática.

O Carnaval de resistência surge do movimento fluido que pensa e atua em redes e que leva a criatividade e o prazer para à política. Rejeita as hierarquias sociais, a divisão entre atores e espectadores, confunde os gêneros, insiste na participação total e no seu caos criativo imprevisível e nos enfrenta com tudo aquilo que a sociedade de bem precisa controlar (https://www.facebook.com/pages/Carnavandalirizacao).

O objeto se apresenta por nuances, fluxos, dinâmicas, formas de enunciação. Partimos também da premissa de um fenômeno que merece atenção diante de um momento histórico-

\section{POLÊM!CA | Revista Eletronica da aej}


social do Brasil, da cidade do Rio de Janeiro, um corpo-manifestação que começa a se ressignificar a partir das manifestações de junho de 2013.

Uma perspectiva que também se enuncia na rede de relações de arteativismo, no que diz respeito à emergência de uma "forma-protesto", é a maneira como o fluxo de informação presente na dinâmica das redes sociais influencia a forma de mobilização para fora da internet $^{8}$. A crítica de dança e professora Helena Katz (PUC-SP), em entrevista ao portal Idança, fala um pouco sobre esse novo "corpo-manifestação" que surge a partir da cognição do mundo online. Sobre as manifestações de junho de 2013, ela diz:

O símbolo maior disso, no meu entender, foi como essa manifestação se corporifica em cartazes individuais do tamanho de um corpo; cada corpo com seu cartaz. Numa direção muito diferente das faixas longas que todo mundo segura e caminha junto, isso me parece realmente o cartaz twitter; é a manifestação de uma frase. Ela sozinha é fraca, mas uma precisa rebater na outra. Parece-me que esse tipo de manifestação é possível porque a vida online e off-line estão borradas, não têm mais a separação habitual que se pensava quando se começou a investigar o mundo virtual no final dos anos 1980 e, especialmente, dos anos 1990 (KATZ, 2013).

A mobilização não se dá apenas em "forma-palanque", em que alguns poucos reproduzem verdades prontas, fórmulas de construção de discurso, a serem repetidas, atendendo muitas vezes a um apelo partidário. Também não se dá apenas pela exploração de uma subjetividade "revolucionária", própria de grupos jovens que urgem pela participação na construção de um plano nacional. Tampouco se dá em "forma-mártir"9, em que um líder, representante experiente de "revoluções" incita uma coletividade a também ser mártir.

No livro "Insurgências Poéticas: arte ativista e ação coletiva" de André Mesquita (2008), o autor inaugura seu pensamento, logo na introdução, falando sobre a construção de uma contra história da arte "dissidente", passada de coletivo para coletivo, de movimento para movimento: "Quando a estética se aproxima da política em momentos de guerra, conflitos, manifestações e crises, insurgências poéticas engendram novos modos de ação coletiva." (MESQUITA, 2008, p. 29).

O enfoque histórico aqui interessa como uma das evidências relevantes dessa rede de arteativismo. O aspecto histórico abre um pressuposto para o "fazer arte" e para o "fazer

\footnotetext{
${ }^{8}$ As mobilizações, via redes sociais, são um fenômeno ainda anterior, poderíamos localizar um marco dessas dinâmicas desde a chamada "Primavera Árabe" (2011) e os sucessivos movimentos anticapitalismo de "Occupy".

${ }^{9}$ Em 2001, participei de um encontro universitário (ENU), promovido pelo MST, na UNICAMP. Nunca me esqueci da fala de João Pedro Stédile, líder do movimento: "revolução se faz com arma e sangue".
} 
político", que serve como referência para outras iniciativas. A rede, mais do que um sistema ou organização, se dá pela relação, que se torna potente com a internet e revela aspectos de colaboração, mobilização e produção de conteúdo de forma autônoma, que antes era restrito ou improvável. Ou seja, a perspectiva histórica da rede coloca em relação o coletivo "Atelier de Dissidências Criativas" com outros coletivos e/ou movimentos, em outros cenários, nacionais ou internacionais, que possuem em comum a utilização estética no discurso político - ou será a utilização política no discurso estético?

Esta dúvida também acompanha a pesquisa, pois partimos da premissa de que há uma modificação no enunciado da arte ativista, em que esta não poderia ser identificada totalmente como arte, nem como protesto. É um ser híbrido que transita entre essas duas "expressões". Isso fala muito da premissa de uma "forma-protesto" que se modifica. O deslocamento de um pressuposto político, em seu formato tradicional de manifestação, em uma expressão artística que, sozinha, também não poderia ser previamente definida como arte. Por isso, também a opção em nomear "forma-protesto"; a palavra forma e o hífen que liga as duas palavras servem como estratégia de leitura para uma ideia de um fenômeno que se dá em rede, não está finalizado como definição ou conceito.

Por fim, o "protesto" hoje se estende para além do ato físico, está intimamente ligado com sua repercussão nas redes sociais, em especial o Facebook. As redes sociais estão presentes na organização coletiva para a ação (divulgação do ato, página, evento, etc.), mas também está presente no ato em si. As imagens estáticas ou fílmicas que registram o ato, bem como as adesões de nomes e sobrenomes a perfis pessoais, ou de logos e banners, complementam a ação que se dá na rua.

Partimos da premissa que as transformações inauguradas com as novas tecnologias de comunicação, como as redes sociais, por exemplo, modificam também a nossa experiência com as ações de manifestação política a que esse trabalho se propõe a pensar. Hoje podemos observar que a "presença" não se dá apenas na forma física, mas também pela experiência virtual. Dessa forma, a documentação online, bem como o compartilhamento de informações e os fóruns de produção e organização de ações em grupos da internet, enfatizam a experiência física do ato. Neste aspecto, as próprias imagens ganharam corpo, dizendo em si mesmas as nuances entre arte e ativismo.

\section{POLÊM!CA | Revista Eletronica da Uej}




\section{Um choque de amor}

Figura - 2: Nossa Copa é na rua: abertura. / Leo Nabuco, 12/06/14.

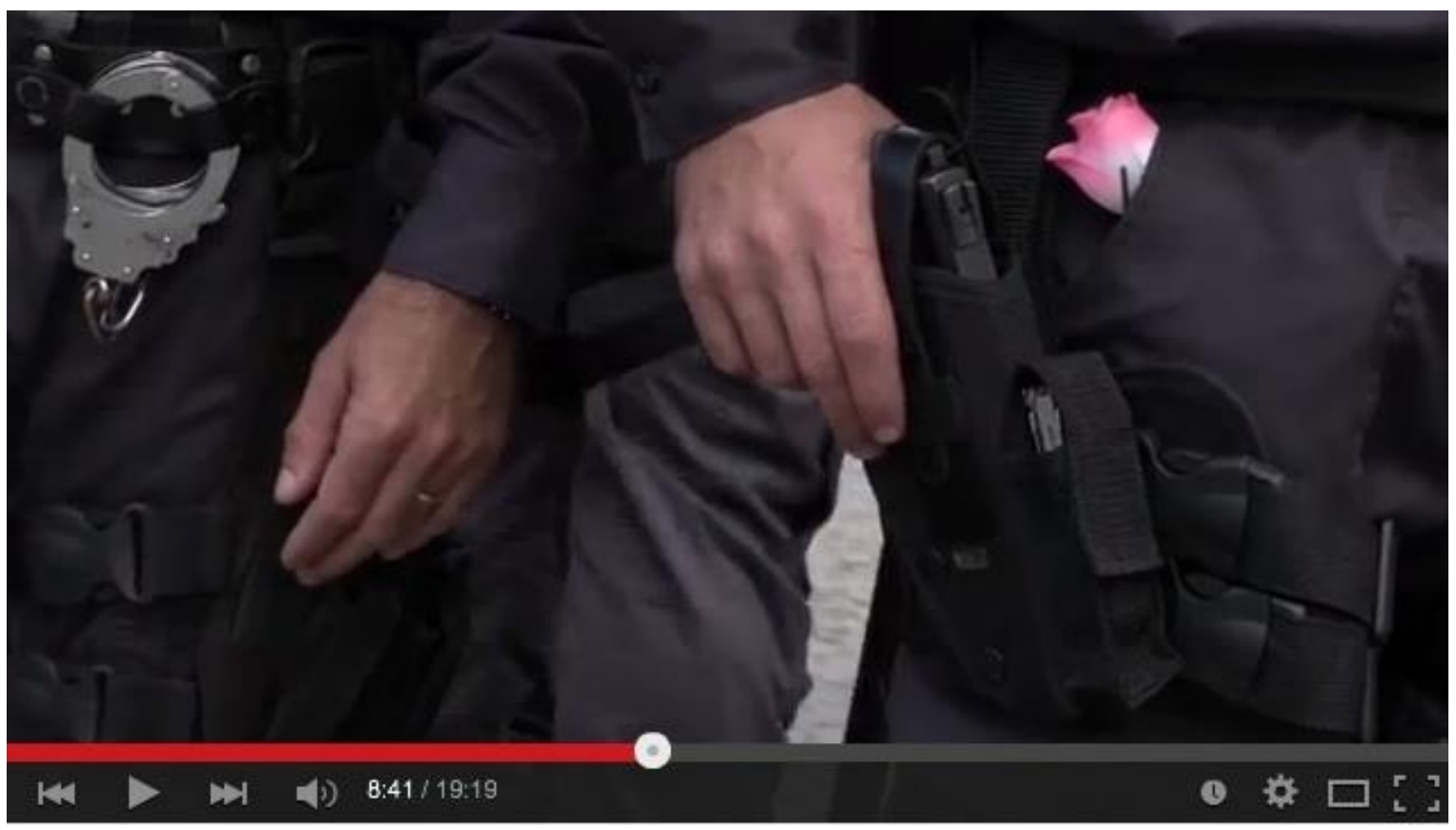

Fonte: https://www.youtube.com/watch?v=c_FawAyq_VM\&list=PL9bg-v00w0IxX46jXC89Huet1R7WP_4Eb.

Acima, uma imagem do filme de Leo Nabuco, um dos integrantes do "Dissidências", que registra o primeiro ato anticopa, no dia 12 de junho de 2014, estreia da Copa no Brasil. A imagem carrega um forte conteúdo simbólico: ao lado da mão que repousa sobre a arma, uma rosa salienta-nos à vista, no bolso do policial que "acompanha" a manifestação, minutos depois de um desentendimento entre polícia e manifestantes. A imagem da rosa sugere doçura, em meio a um cenário de policiais armados. Um colorido que destoa da farda preta, e, no entanto, está ali guardada, não foi dispensada, nem escondida. Ao contrário, mantém-se como lembrança de que antes de um policial, há um sujeito, que afeta e é afetado pelo mundo, nesse caso pelo protesto, pela forma lírica de protestar. Um presente do grupo fantasiado que protesta em glitter, cor de rosa e flor.

Noticiado internacionalmente, o fenômeno da carnavandalirização apresenta uma prática que mistura estética com política, humor com estratégia, e reinventa uma forma de protestar que em seu formato mais tradicional talvez já esteja ultrapassada, desinteressante, 
repetitiva. No portal de notícias online, "Salon”, o jornalista Greg Scruggs fala um pouco sobre o aspecto criativo dos atos de protesto do Carnavandalirização:

Under the banner of Carnavandalirização (a portmanteau of Carnival, vandalism and lyricism), this loose-knit coalition of artists, human rights promoters, designers, LGBT activists, musicians, actors and of course carnavalescos (...) is going for 'quality over quantity', as one participant said in a telephone interview, to pursue "creative dissidence" with provocative performances, searing critiques, clever plays on words and a willingness to put their bodies on the line (SCRUGGS, s/p, 2014). ${ }^{10}$

John Jordan, artista e ativista residente do Reino Unido, em texto escrito sobre os protestos do "Carnaval anticapitalismo", ocorrido em 18 de junho de 1999, em Londres, fala sobre as diversas facetas desse tipo de ação. Gostaríamos de reproduzir aqui um trecho de seu texto, que diz respeito à "subversão pela estética e prazer", que também se aplica a este estudo:

The inclusive embrace of carnival with its passionate liberation of bodies and its collective socio-erotic spell celebrates a politics that sees qualitative desires as just as important as material needs, refusing to separate the need for material survival from the pleasures of living. (JORDAN, s/p, 2005) ${ }^{11}$.

O que parece ser mais instigante é a maneira como a expressão de guerrilha lírica parece estar comprometida com a manifestação política, mas também com uma prática individual e coletiva de estar no mundo, aqui explicitada pelo prazer, pela festa, pela fantasia, pelo colorido, pela purpurina, por performances estéticas. Sua bandeira não é do confronto direto à represália policial, por exemplo, mas à subversão desse confronto, como o "choque de amor" ou o bloco dos "Pink Bloc".

Figura - 3: Foto divulgação: $2^{\circ}$ ato anticopa / Praia de Copacabana. 28/06/14

\footnotetext{
${ }^{10}$ Tradução da autora: "Sob a bandeira da Carnavandalirização (um composto entre Carnaval, vandalismo e lirismo), um grupo de artistas, promotores de direitos humanos, designers, ativistas LGBT, músicos, atores e, é claro, carnavalescos (...) buscam 'qualidade, em vez de quantidade', conforme afirmado por participante em entrevista por telefone, perseguem 'dissidências criativas' com performances provocativas, críticas abrasivas, jogos de palavras inteligentes e disposição em colocar seus corpos na rua." Disponível em: http://www.salon.com.

${ }^{11}$ Tradução da autora: "A abrangência inclusiva do carnaval com sua liberação passional de corpos e seu encantamento sócioerótico coletivo, celebra uma política que enxerga desejos qualitativos tão importantes quanto necessidades materiais, se recusando a separar a necessidade de sobrevivência material dos prazeres de viver.”. Disponível em: http://eipcp.net/transversal/1007/jordan/en.
}

\section{POLÊM!CA | Revista Eetroronica da veri}




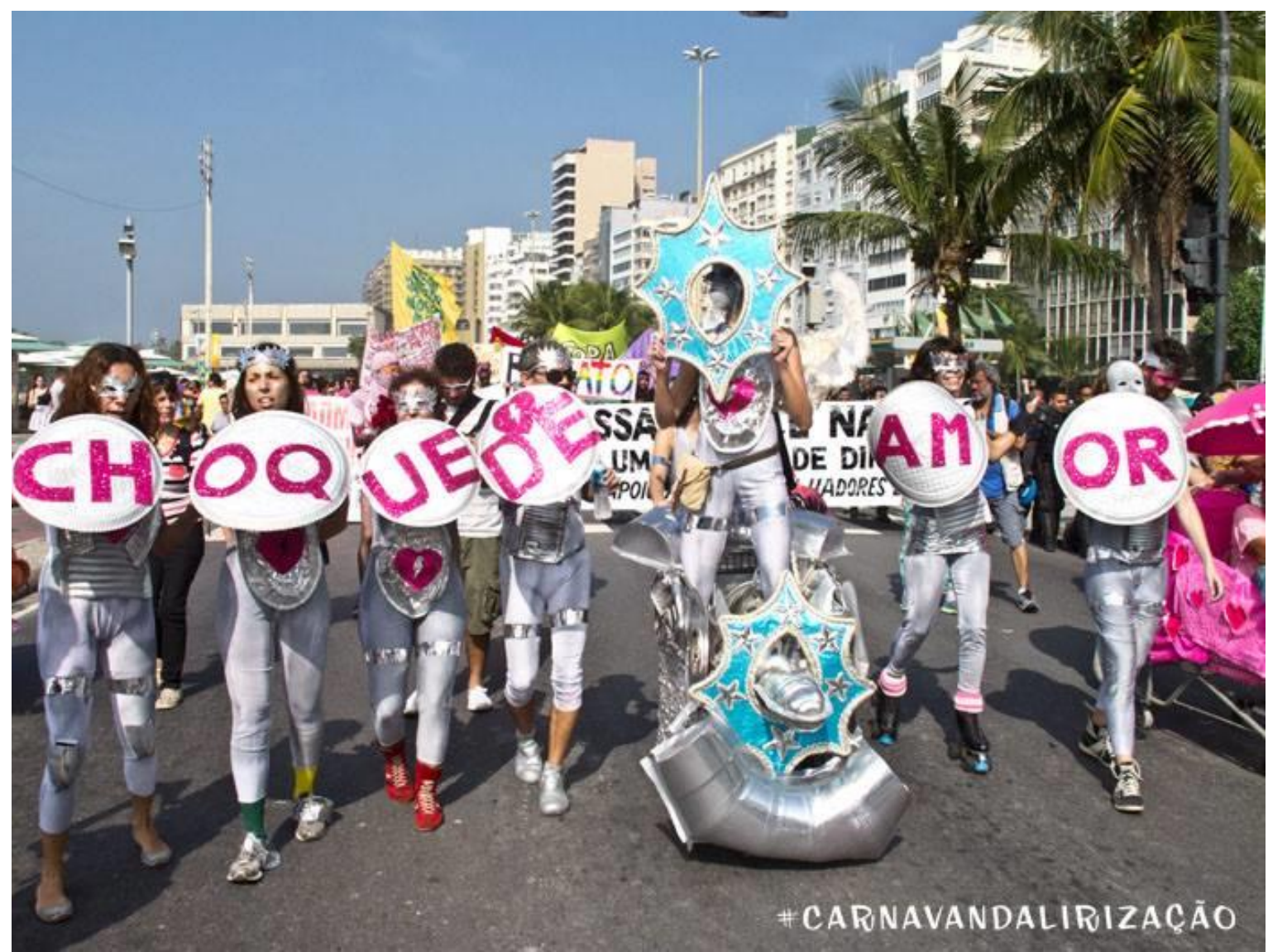

Fonte: https://www.facebook.com/pages/Carnavandalirizacao.

No dia 28 de junho, dia de jogo do Brasil contra o Chile, aconteceu o ato anticopa junto com o Dia do Orgulho LGBT. Ao final da caminhada pela orla de Copacabana foi produzida uma festa after ato. Uma bicicleta equipada com TV de LED de 42”, equipamento de som e gerador de energia, foi colocada na areia da praia do Leme, alguns metros depois do centro da FIFA, o FIFA Fan Fest, que reunia milhares de torcedores. Na televisão passava o jogo do Brasil, enquanto em um microfone aberto uma "performance de locução" acontecia. Ao grupo de manifestantes, juntaram-se outras pessoas para ver o jogo, ou apenas para participar da festa. Havia também uma arara com camisas "anticopa" à venda, DJ nos intervalos e no final uma performance do grupo carnavalesco "Bunytos de Corpo".

\section{Considerações Finais}

Ao entrarmos em contato com a "forma-protesto" do carnavandalirização, pudemos observar que o discurso de arteativismo expressa algo de peculiar à contemporaneidade. Existe um forte potencial simbólico quando a polícia repousa a mão na arma ao lado de uma 
rosa que guarda no bolso. Interessou-nos aqui investigar o impacto social disso que estamos chamando de "forma-protesto", partindo da premissa de que há uma reinvenção na maneira de estar em uma manifestação, que também está conectada com a imagem que gera de si nas redes sociais.

Ao participar do ato e da festa after ato, ficou evidente para mim, como observadora participante, que o ato festivo era atraente e prazeroso. A ação política atravessada por nuances estéticas e lúdicas convida e seduz as pessoas, não necessariamente engajadas em nenhuma atividade a priori, apenas pelo prazer de participar. É possível observar que há uma contaminação de discurso carnavandalirizante que "contagia" o público presente, ainda que sua participação inicial seja descompromissada e dure apenas aquele momento.

A pesquisa optou por seguir um certo grupo, que mais serviria como input de um desencadeamento que se dá em rede, pois aposta que acompanhar os fluxos e dinâmicas do "Dissidências" fala muito de um momento atual e localizado da experiência política. Ao relacionar esse grupo com uma rede de arteativismo e investigar de que forma essas conexões podem ser inseridas num processo de mediação tecnológica, as narrativas tentam apresentar algumas nuances possíveis na produção de sentido na atualidade.

A partir desse ponto de encontro, outras conexões poderão ser rastreadas, como parte da construção de um pensamento que acompanha fluxos, que não está comprometido com o fim, mas sim com o processo. E, ainda, como processo, uma gama de contextos são possíveis de serem desenhados nessa rede, outros carnavais de ação política, outras imagens de carnavandalirização, outras práticas de arteativismo.

\section{Referências}

AZAMBUJA, P. K. Cognicão e mediacão técnica: passagem analógico-digital da recepção de TV sob a ótica da Teoria Ator-rede. 2012. 216f. Tese (Doutorado) - Instituto de Psicologia, Universidade do Estado do Rio de Janeiro, Rio de Janeiro, 2012.

DELEUZE, G.; GUATTARI, F. Mil platôs: capitalismo e esquizofrenia. Rio de Janeiro: Ed. 34, 1995. 96 p. v. 1.

O que é a Filosofia. Rio de Janeiro: Ed. 34, 1997.

FREIRE, L de L. Seguindo Bruno Latour: notas para uma antropologia simétrica. Rio de Janeiro: Comum, 2006. v. 11, n. 26. pp. 46-65.

GONÇALVES, F. N. Tecnologia e cultura: usos artísticos da tecnologia como prática de comunicação e laboratório de experimentação social. Revista FAMECOS, Porto Alegre, v.1, p.100-110, 2009. 
GORINI, P. A Rede da Dança: uma cartografia em movimento. 2012. 148f. Dissertação (mestrado) - Faculdade de Comunicação Social, Universidade do Estado do Rio de Janeiro, Rio de Janeiro, 2012.

JONHSON, S. Emergência: a vida integrada de formigas, cérebros, cidades e softwares. Rio de Janeiro: Jorge Zahar, 2003.

JORDAN, J. Notes Whilst Walking on "How to Break the Heart of Empire". Website do Instituo Europeu para políticas culturais progressivas. Disponível em: 〈http://eipcp.net/transversal/1007/jordan/en〉. Acesso em: ago. 2015.

KATZ, H. Como é que a gente pode participar de um país que quer transformações? In: ROSA, Luisa. Helena Katz comenta o corpo nas manifestações. Disponível em: <http://idanca.net/como-e-que-a-gente-podeparticipar-de-um-pais-que-quer-transformacoes/>. Acesso em: jul. 2015.

LAW, J. Notes on the Theory of the Actor Network: ordering, strategy and heterogeneity. CENTRE FOR SCIENCE STUDIES: Lancaster University, Reino Unido, 1992.

LATOUR, B. Jamais fomos modernos. Rio de Janeiro: Editora 34, 1994.

Reensamblar lo Social: una introducción a la teoría del actor-red. 1 ed. Buenos Aires: Manantial, 2008.

LIVE ART DEVELOPMENT AGENCY et al. In time: a collection of live art case studies. Reino Unido: LADA, 2010.

MESQUITA, A. Insurgências Poéticas: arte ativista e ação coletiva (1990-2000). 2008. 429f. Dissertação (mestrado) - Faculdade de Filosofia, Letras e Ciências Humanas, Universidade de São Paulo, São Paulo, 2008.

PASSOS, E.; KASTRUP, V.; ESCOSSIA, L. (Org.). Pistas do método da cartografia: pesquisa-intervenção e produção de subjetividade. Porto Alegre: Sulina, 2009.

SCRUGGS, G. "Then one of our glitter terrorists fired his gun": The World Cup's wild, naked antigovernment protests. Salon, portal internacional de notícias. Disponível em:

<http://www.salon.com/chromeo/article/then_one_of_our_glitter_terrorists_fired_his_gun_the_world_cups_wild _naked_anti_government_protests/>. Acesso em: jul. 2014.

Recebido em: 28/07/2015.

Aceito em: 04/01/2016. 